\title{
Removal of Congo Red and Acid Yellow 36 Dye Using Orange Peel and Rice Husk as Absorbents
}

\author{
Y.C.WONG ${ }^{1 *}$, K.N. RANJINII ${ }^{1}$ and W.A.WAN-NURDIYANA ${ }^{1}$ \\ ${ }^{1}$ Faculty of Agro Based Industry, University Malaysia Kelantan, \\ Jeli Campus, Locked Bag 100, 17600 Jeli, Kelantan, Malaysia. \\ ${ }^{*}$ Corresponding author E-mail: yeeching @umk.edu.my
}

http://dx.doi.org/10.13005/ojc/300217

(Received: March 02, 2014; Accepted: April 06, 2014)

\begin{abstract}
Many researchers have identified the capability of agricultural wastes as absorbents to remove different types of pollutants including dyes. This study represents the use of orange peel (OP) and rice husk $(\mathrm{RH})$ to remove two types of dye, Congo Red (CR) and Acid Yellow 36 (AY 36) dye and provides simple comparison between granular form of $\mathrm{OP}$ and $\mathrm{RH}$ and activated form of $\mathrm{OP}$ and $\mathrm{RH}$. Both types of dyes are toxic and can cause severe problems to the environment. Factor such as absorbent dosage was studied. Batch absorption studies were conducted at 27 ÚC with constant stirring at $150 \mathrm{rpm}$ for 2 hours and absorbent dosage of 0.2 to $1.0 \mathrm{~g}$. The results showed that the activated form of $\mathrm{OP}$ and $\mathrm{RH}$ had the highest removal percentage of $\mathrm{CR}$ and AY 36 dyeswhich were up to $100 \%$ removal. This study indicates that OP and RH could be employed as low cost materials for the removal of textile dyes from effluents.
\end{abstract}

Key words: Dye removal, Congo red, Acid yellow 36, Absorbent, Orange peel, Rice husk.

\section{INTRODUCTION}

Concerns for environmental crisis began during second half of $20^{\text {th }}$ century due to various factors and undesirable experiences. The past mistakes from over-utilization of natural resources and harnessing the forces of nature for the benefit of growing human population and the concurrent apathy to environmental regeneration and conservation have begun to boomerang on the unsuspecting world population. Evidence of these phenomena can be seen in the spread of desertification floods, soil maladies, draughts, urban congestion, extinction of/or threat to countless species of plants and animals that made the ecosystem an unchecked pollution of land, water and air (Ghosh, 2008).

The Department of Environment (DOE), Malaysia has been continuously monitoring river water quality to classify the pollution level and detect changes in the local rivers water quality. The Water Quality Index (WQI) is used as a basis for assessment of watercourse in relation to pollution 
load categorization and designation of classes of beneficial uses as stipulated in the National Water Quality Standards for Malaysia (NWQS). According to river water quality status in 2011 , out of 464 rivers monitored, a total of 275 (59.3\%) were found to be clean, $150(32.3 \%)$ slightly polluted and $39(8.4 \%)$ polluted. As in previous years, the major pollutants detected were Biochemical Oxygen Demand (BOD), Ammoniacal Nitrogen $\left(\mathrm{NH}_{3}-\mathrm{N}\right)$ and Suspended Solids (SS). High BOD can be attributed to untreated or partially treated sewage and discharges from agro-based industries and manufacturing industries (Zulkifli, Choong \& Noor, 2011).

Dye is the molecule that produces color on fabric. The color in wastewater is the dye that is not fixed in the dyeing of fibre, yarn, fabric or garments being processed. The degree to which colorin the wastewater may be a problem, depending on the type or class of dye being used and the degree to which the textile effluent contributes to the flow of the receiving body (Hardin, 2007).

Environmental pollution by discharge of dye-containing effluents represents a serious ecological concern in many countries. Public demands for color-free discharges to receiving waters have made decoloration of a variety of industrial wastewater a top priority. The current existing techniques for dye removal have several drawbacks such as high cost, low efficiency, use of large amounts of chemicals and formation of toxic sub-products (Rodriguez, 2009). It is reported that $90 \%$ of the organic chemicals and auxiliaries in pretreatment and dyeing operation do not stay on the fibre, whereas the reverse is true on the finishing treatment (Christie, 2007).

The decolorization and usage of reactive dyes of textile industry wastewater is a worldwide problem. Regulatory agencies are interested in new, efficient and improvised decolorization techniques. Bioremediation of textile effluent is seen as a good solution due to its low-cost, sustainable and acceptable technology. Besides that, there are many other methods in treating textile wastewater; sorption, oxidation reaction, membrane filtration and et cetera(Pereira \&Madalena, 2012).
Absorption is the process by which one substance(gas, liquid or solid) is taken into the body of another substancewhere the molecules or ions penetrate into the interior of another substance. It is also known as the process in which one material (the absorbent) takes up and retains another (the absorbate) with the formation of homogeneous mixture having the attributes of a solution (Lee, 2005).

According to U.S. Department of Energy (DOE), biomass is any organic matter available on renewable basis, including crops, trees, agricultural crop wastes and residues, and other waste materials. Rice husk $(\mathrm{RH})$ is a major by-product of rice farming. Environmental regulation limits disposal of the husk in landfills (Ravindra, Moray \& Thomas, 2003). With this available large source of rice husk and easily obtainable agricultural waste, orange peel (OP) is convenient to be used in this thesis as the adsorbent in removing Congo Red and Acid Yellow 36 dye.Primary colors are pure or fundamental colors that cannot be achieved from a mixture. Red, yellow and blue colors form the primary triad (Alpert et al., 2004). Secondary color is color obtained by mixing equal parts of two primary colors. Green, orange and violet are secondary colors(Hornung, 2004). Both Congo Red and Acid Yellow 36 are among the prime colors in which other colors are made from. The purpose of conducting a study on the removal of these two prime colors is to ensure that the other colors made from these prime colors can be removed too by using the same method.

The objectives of the research areto determine the effectiveness of $\mathrm{RH}$ and $\mathrm{OP}$ in removal of Congo Red and Acid Yellow 36 dye from textile wastewater, to investigate the potential of $\mathrm{RH}$ and OP pretreated into activated carbon as dye removal and to optimize the removal of dye by varying the size of absorbent, $\mathrm{OP}$ and $\mathrm{RH}$ pretreated with acid into active carbon, agitation time and initial concentration.

\section{EXPERIMENTAL}

Experimental variables to be considered were

(i) sizes of absorbents $(>150 \mu \mathrm{m},>425 \mu \mathrm{m})$;

(ii) acid treated and non-treated absorbents; 
(iii) agitation time $(30,60,90,120 \mathrm{~min})$; and

(iv) different initial concentrations (20, 40, 60, $80,100) \mathrm{mg} / \mathrm{L}$.

\section{Preparation of activated carbon}

The raw materials used for activated carbon (AC) preparation wereOP and $\mathrm{RH}$. To produce the $\mathrm{AC}$, dewatered $\mathrm{OP}$ and $\mathrm{RH}$ were mixed with concentrated $\mathrm{H}_{2} \mathrm{SO}_{4}(17.5 \mathrm{M})$ and dried in air at room temperature for 24 hours. $300 \mathrm{~g}$ of the dried materials were put in an oven and heated at $180^{\circ} \mathrm{C}$ for 24 hours. The samples were then allowed to cool at room temperature in an inert atmosphere. The product resulted from the activation step was blended in order to form granular AC and washed with $3 \mathrm{M} \mathrm{NaOH}$. The carbon product was then vacuum-filtered through filter paper and washed repeatedly with distilled water to remove all traces of acid and alkaline until $\mathrm{pH}$ of rinsed water was constant. The product was thenwet-screed and dried at $80^{\circ} \mathrm{C}$ for 24 hours. Figure 1 showed the simplified chart of the methods used.

\section{Dye solution preparation}

For the preparation of aqueous solution, a stock of CR $(1000 \mathrm{mg} / \mathrm{l})$ and AY $36(1000 \mathrm{mg} / \mathrm{l})$ dyes were prepared and diluted to the required initial concentration.

\section{Absorption tests}

The study employed the absorption tests of $\mathrm{CR}$ and AY36 dyes on OP and RH absorbents under different experimental conditions; (i) sizes of absorbents (>150 $\mu \mathrm{m},>425 \mu \mathrm{m}$ ); (ii) treated and nontreated absorbents (iii) agitation time $(30,60,90$, $120 \mathrm{~min}$ ) and (iv) different initial concentrations (20, $40,60,80,100 \mathrm{mg} / \mathrm{L})$.

For absorption analysis, a duplicate samples and control were prepared for further treatment analysis. The initial and final concentrations of CR and AY36 were obtained by measuring them with UV-spectrophotometer at 545 $\mathrm{nm}$.

\section{Separation techniques}

For separation between absorbent and solution, the samples were centrifuged at 1,000 rpm for 15 minutes. After centrifugation, the samples were removed and the supernatants were measured using UV-spectrophotometer. The final concentration was measured using UVspectrophotometer to determine the colorthat has been removed from the solution. The process was summarized as shown in Figure 2.

\section{Data analysis}

The data wereanalyzed by calculating the percentage removal of dye and the amount absorbed (in $\mathrm{mg} / \mathrm{g}$ ) using the following equation:

Percentage removal $=100(\mathrm{Ci}-\mathrm{Cf}) / \mathrm{Ci}$

$\mathrm{Ci}$ and $\mathrm{Cf}$ are initial and final concentration (in $\mathrm{mg} / \mathrm{L}$ ) of dye respectively. Blank containing no dye was used for each series of experiments as control. The average values of 3 duplicates were obtained and analyzed.

\section{Statistical analysis}

All data in this study were subjected to analysis of variance procedure (One-Way ANOVA). The one way analysis of variance (ANOVA) is an inferential statistical test that checks if any of several means are different from each other. It assumes that the dependent variable has an interval or ratio scale, but it is often also used withordinally scaled data. The datawereanalyzed using Statistical Package for the Social Science (SPSS) software. Even though there were many parameters to be tested in this study, the results were proved to be significant or not separately. This was because the parameters were not related to one another.

\section{RESULTS AND DISCUSSION}

Effect of absorbent dosage on the percentage of dye removal for different size of orange peel and rice husk in Congo Red and Acid Yellow 36 dyes

Figure 3 showed the effect of absorbent dosage against percentage of dye removal of Congo Red (CR) on different sizes of orange peel; i) raw orange peel $<425 \mu \mathrm{m}$ (OP150), ii) raw orange peel $>425 \mu \mathrm{m}$ (OP425) and different sizes of rice husk; i) raw rice husk $<425 \mu \mathrm{m}(\mathrm{RH} 150)$, ii) raw rice husk $>425 \mu \mathrm{m}(\mathrm{RH} 425)$. A series of absorption experiment was carried out with different absorbent dosages $(0.2,0.4,0.6,0.8,1.0 \mathrm{~g})$ at fixed 
concentration of $60 \mathrm{mg} / \mathrm{L}$ at constant volume of dye solution $(50 \mathrm{~mL})$ with constant rotation speed at 150rpm for 2hours. Similarly, the temperature was kept constant at $27^{\circ} \mathrm{C}$.

From Figure 3 , it can be seen that the highest percentage of removal of dye by OP 150 and OP 425 was shown at absorbent dosage $1.0 \mathrm{~g}$ in CR dye. Dye removal percentage of OP 150 was $95.49 \%$ and OP 425 's was $88.66 \%$. The lowest percentage of dye removal by both OP 150 and OP 425 were at $0.2 \mathrm{~g}$ absorbent dosages which were $77.19 \%$ and $72.18 \%$ respectively. The CR dye was absorbed more effectively by the smaller size of orange peel (OP 150).

Table 1: T-test significant result

\begin{tabular}{|c|c|}
\hline Absorbent Dosage on CR & Significance \\
\hline OP 150 & 0.000 \\
\hline OP 425 & 0.000 \\
\hline RH 150 & 0.001 \\
\hline RH 425 & 0.000 \\
\hline AC OP & 0.008 \\
\hline $\mathrm{AC} \mathrm{RH}$ & - \\
\hline Absorbent Dosage on AY 36 & Significance \\
\hline OP 150 & 0.001 \\
\hline OP 425 & 0.002 \\
\hline RH 150 & 0.000 \\
\hline RH 425 & 0.003 \\
\hline AC OP & 0.009 \\
\hline $\mathrm{AC} \mathrm{RH}$ & 0.012 \\
\hline Initial concentration on $\mathrm{CR}$ & Significance \\
\hline OP150 & 0.000 \\
\hline OP 425 & 0.000 \\
\hline RH 150 & 0.000 \\
\hline RH 425 & 0.000 \\
\hline Initial concentration on AY36 & Significance \\
\hline OP 150 & 0.026 \\
\hline OP 425 & 0.030 \\
\hline RH 150 & 0.001 \\
\hline RH 425 & 0.001 \\
\hline Agitation time on $\mathrm{CR}$ & Significance \\
\hline OP 150 & 0.000 \\
\hline $\mathrm{RH} 150$ & 0.000 \\
\hline Agitation time on AY 36 & Significance \\
\hline OP 150 & 0.022 \\
\hline RH 150 & 0.010 \\
\hline
\end{tabular}

Meanwhile the $\mathrm{RH}$ samples also showed that the highest percentage of dye removalby $\mathrm{RH}$ 150 and $\mathrm{RH} 425$ were at $1.0 \mathrm{~g}$ absorbent dosage in $\mathrm{CR}$ dye. RH 150 percentage of dye removal was $88.33 \%$ while $\mathrm{RH} 425$ was $81.67 \%$. The lowest percentage of dye removal by both $\mathrm{RH} 150$ and $\mathrm{RH}$ 425 was at absorbent dosage 0.2 gwhich was 48.33 $\%$. The CR dye was found to be absorbed more effectively by smaller size of rice husk (RH 150). The percentage of $\mathrm{CR}$ dye removal was highest when OP was used as absorbent.

Meanwhile Figure 4 showed the effect of absorbent dosage against percentage of dye removal of Acid Yellow 36 (AY 36) on different sizes of orange peel; i) raw orange peel $<425 \mu \mathrm{m}$ (OP150), ii) raw orange peel $>425 \mu \mathrm{m}(\mathrm{OP} 425)$ and different sizes of rice husk; i) raw rice husk $<425 \mu \mathrm{m}(\mathrm{RH} 150)$, ii) raw rice husk $>425 \mu \mathrm{m}$ ( $\mathrm{RH} 425)$. A series of absorption experiment was carried out with different absorbent dosages $(0.2,0.4,0.6,0.8,1.0 \mathrm{~g})$ at fixed concentration of $60 \mathrm{mg} / \mathrm{L}$ at constant volume of dye solution $(50 \mathrm{~mL})$ with constant speed of rotation 150 rpm for 2hours. Similarly, the temperature was kept constant at $27^{\circ} \mathrm{C}$.

From Figure 4, it can be seen that the highest percentage of dye removal by OP 150 and OP 425 was at absorbent dosage $1.0 \mathrm{~g}$ in AY 36 dye. OP 150 showed $88.33 \%$ dye removal and OP 425 dye removal was $81.67 \%$. The lowest percentage of dye removal for both OP 150 and OP 425 was at absorbent dosage $0.2 \mathrm{~g}$ which was 48.33 $\%$. AY 36 dye was absorbed more effectively by the smaller size orange peel (OP 150).

While the RH samples showed that the highest percentage of dye removal of $\mathrm{RH} 150$ and $\mathrm{RH} 425$ was at dosage absorbent $0.8 \mathrm{~g}$ in AY 36 dye. The dye removal percentage for $\mathrm{RH} 150$ was $32.1 \%$ while $\mathrm{RH} 425$ was at $31.8 \%$. The lowest percentages of dye removal by both $\mathrm{RH} 150$ and $\mathrm{RH} 425$ were at absorbent dosage $0.2 \mathrm{~g}$ which were $27.16 \%$ and $22.22 \%$ respectively. AY 36 dye was absorbed more effectively by smaller size rice husk (RH 150). The dye removal percentage of AY 36 is highest when OP was used as absorbent.

Both Figure 3 and Figure 4 showed that smaller size of both $\mathrm{OP}$ and $\mathrm{RH}$ had higher 
absorption rate compared to the larger sizes. The smaller the size of the absorbent, the greater its surface area in which it provides more binding sites for the dye molecules. Besides that, absorbent with smaller size contacts with sorbate faster at the binding site (Asgher \& Bhatti, 2012).
It was also shown that the dye removal rate increases with increasing absorbent dosage. This was due to the increased number of absorbent whichalso increasedthe surface area for dye bindings. This was in agreement with the findings of Khaled et al. (2009). Usage of OP as absorbent

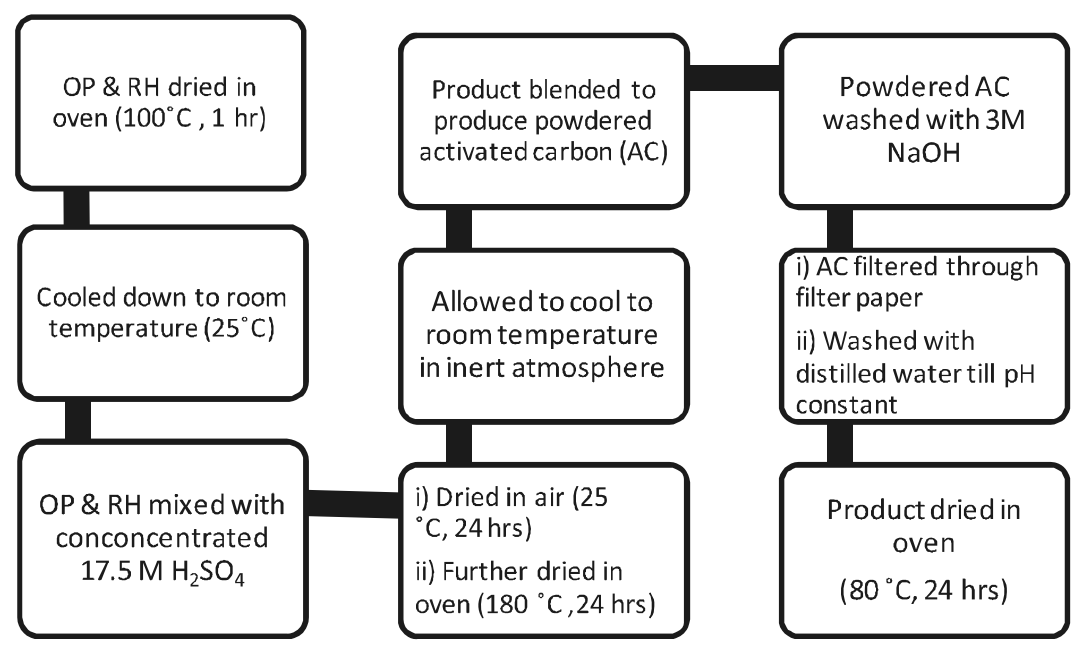

Fig. 1: Simplified form of activated carbon preparation method

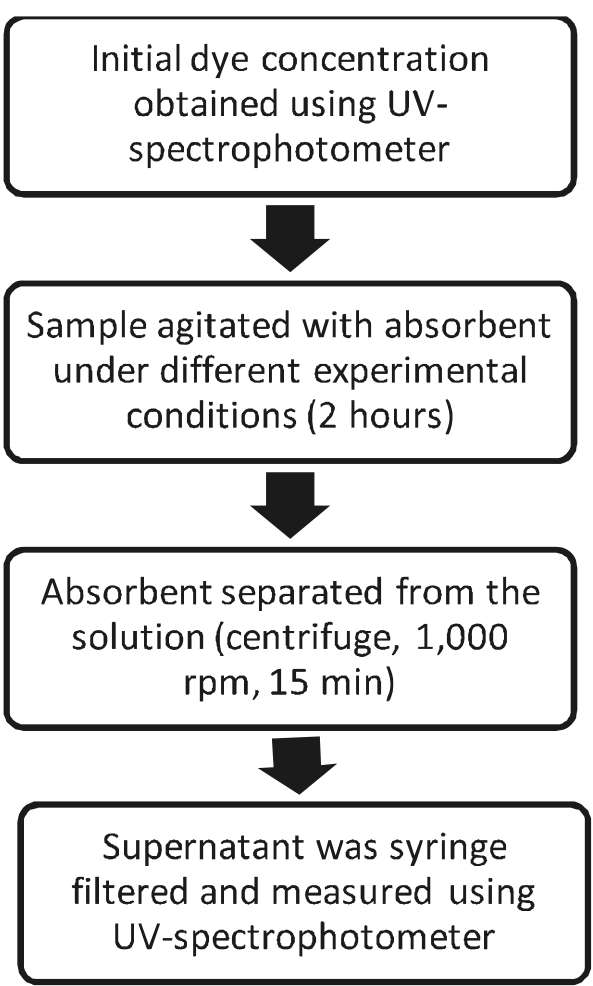

Fig. 2: Separation technique chart gave the highest percentage of dye removal in both CR and AY 36.

OP principally consists of cellulose, pectin, hemicellulose, lignin, chlorophyll pigments and other low molecular weight hydro-carbons (Liang et al., 2010). These components contain various functional groups, such as carboxyl and hydroxyl groups which turned itinto potential absorbent material for removing metal ions from aqueous solutions (Arami et al., 2005).

Since OP is composed of various functional groups, it could also be affected by the $\mathrm{pH}$ of the solutions. Therefore, electrostatic attraction, as well as organic properties and structure of dye molecules and OP could play an important role on dye adsorption on OP. Dried OP with $\mathrm{pH} 4$ has higher tendency of electrostatic attraction compared to $\mathrm{RH}$ with $\mathrm{pH}$ of 5.5. This is because both dyes have an anionic functional group.

At $\mathrm{pH} 4$, a high electrostatic attraction exists between the positively charged surface of 
the absorbent and the anionic dye. Since the $\mathrm{pH}$ of $\mathrm{RH}$ is 5.5 , the electrostatic attraction is lower compared to OP. This indicates the reason why the percentage of dye removal was higher for OP compared to $\mathrm{RH}$. As the $\mathrm{pH}$ increases, the number of positively charged surface site on the absorbent decreases.

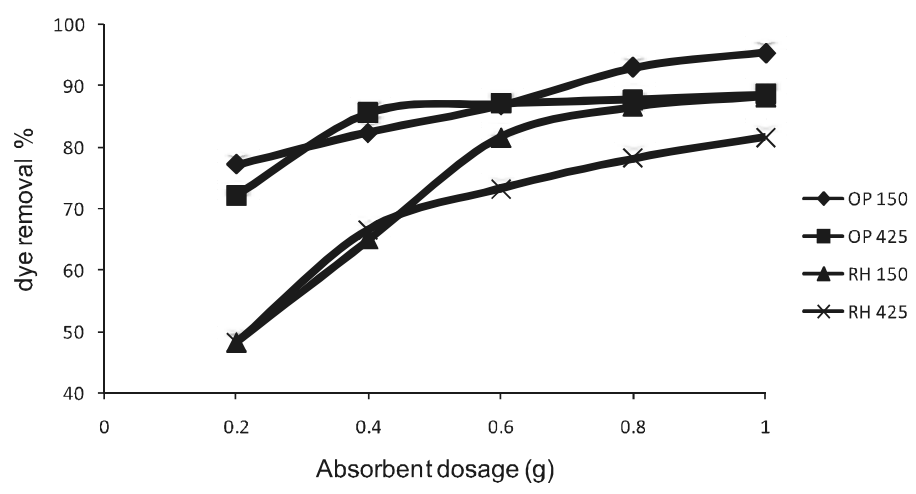

Fig. 3: Effect of absorbent dosage on the percentage of dye removal for OP 150, OP 425, RH 150 and RH 425 in CR

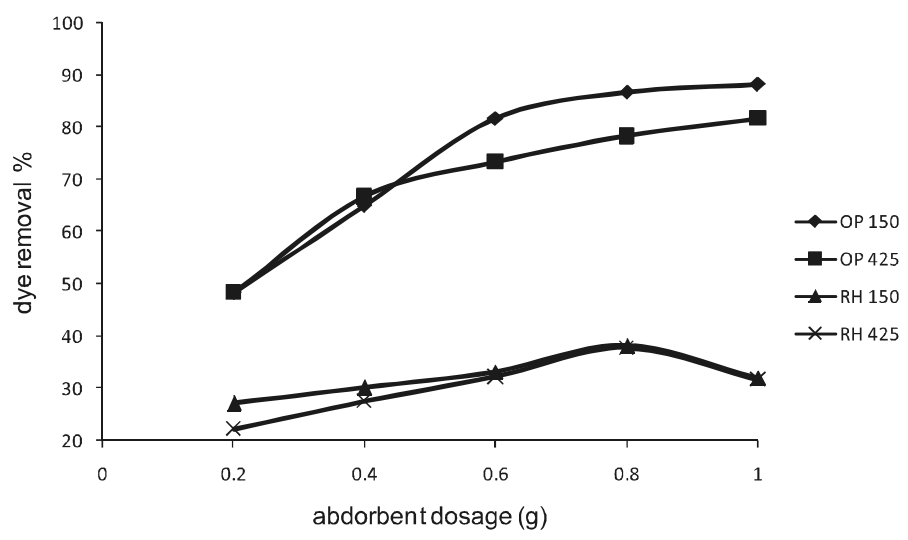

Fig. 4: Effect of absorbent dosage on the percentage of dye removal for OP 150, OP 425, RH 150 and RH 425 in AY 36

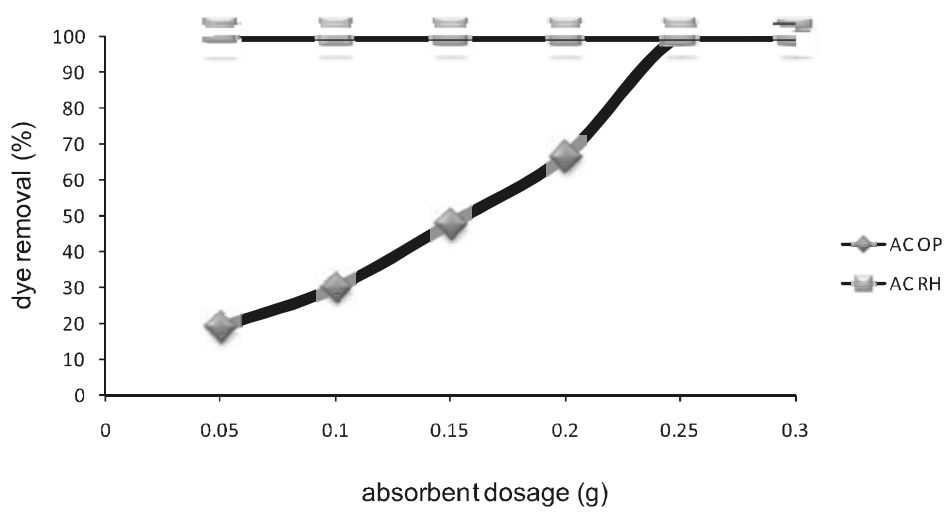

Fig. 5: Effect of absorbent dosage on the percentage of dye removal for AC OP and AC RH in CR 


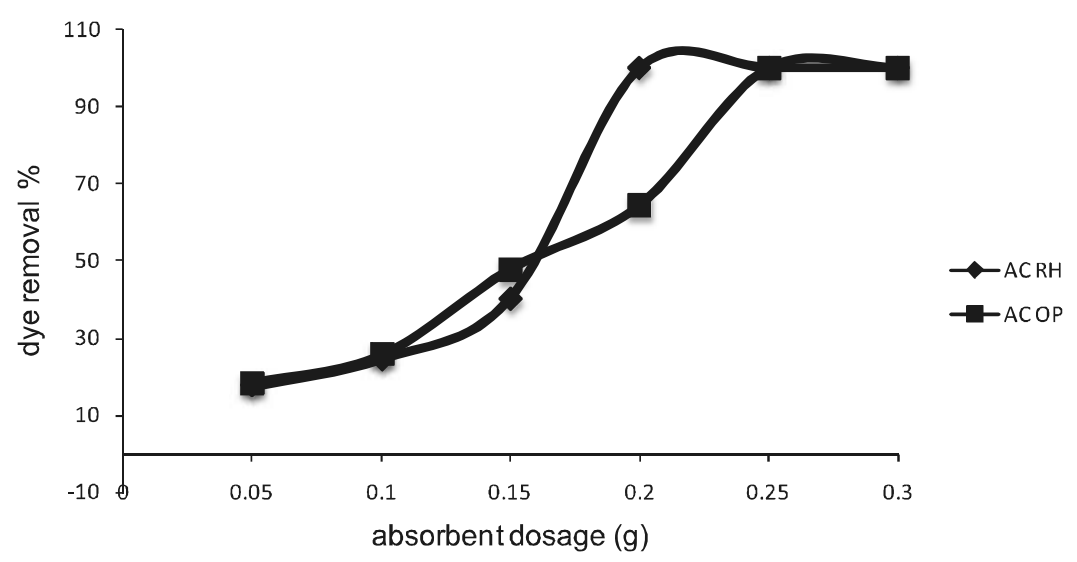

Fig. 6: Effect of absorbent dosage on the percentage of dye removal for AC OP and AC RH in AY 36

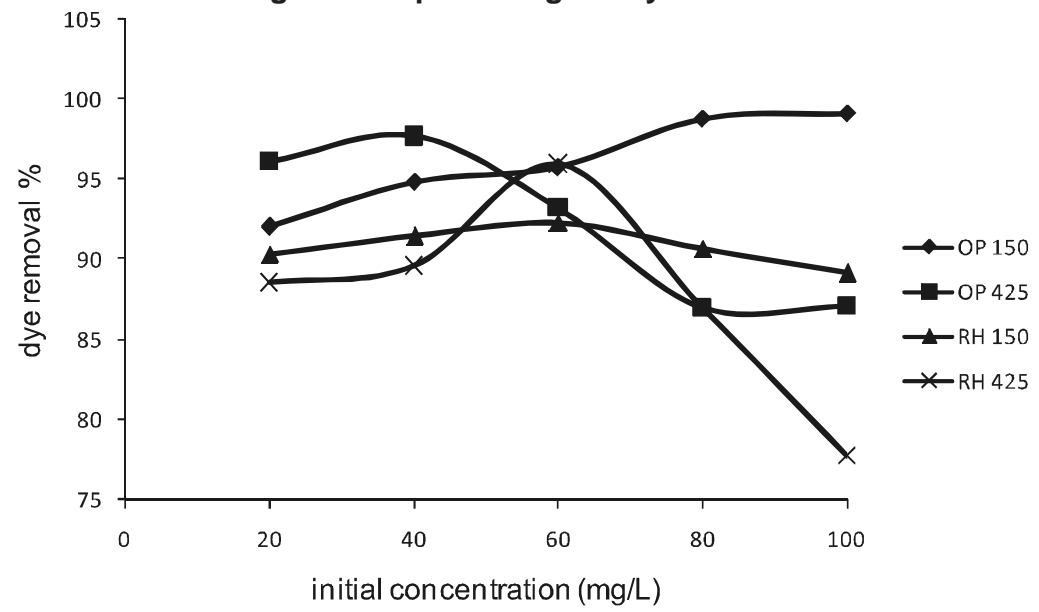

Fig. 7: Effect of initial concentration on the percentage of dye removal for OP 150, OP 425, RH 150 and RH 425 in CR

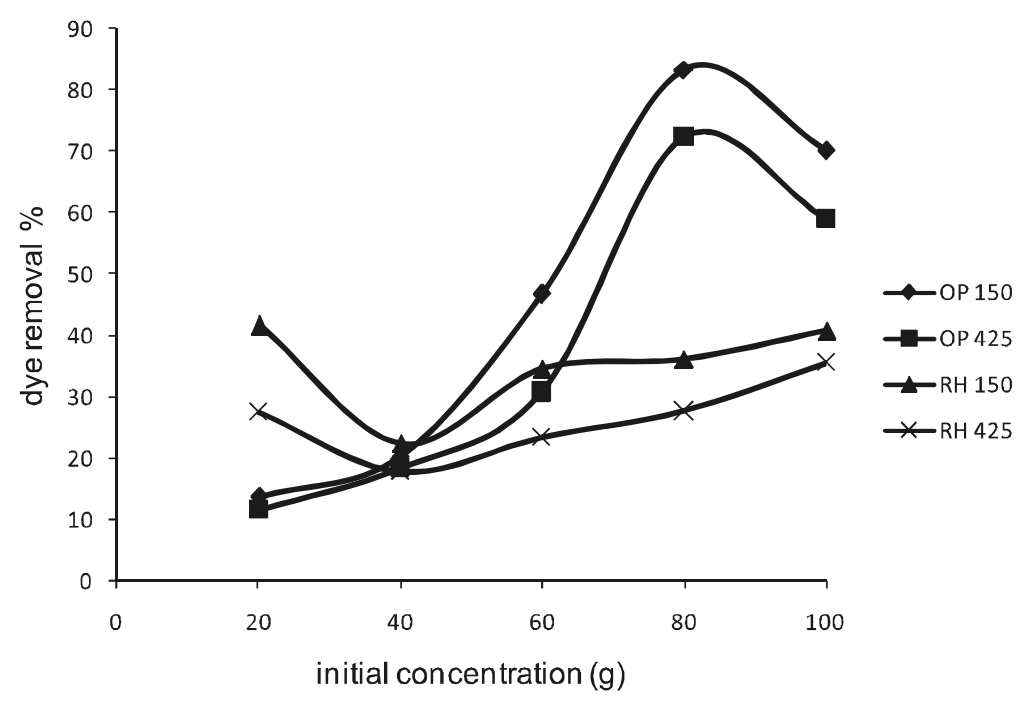

Fig. 8: Effect of initial concentration on the percentage of dye removal for OP 150, OP 425, RH 150 and RH 425 in AY 36 
Effect of absorbent dosage on the percentage of dye removal for acid-treated form of orange peel and rice husk in Congo Red and Acid Yellow 36 dyes

Figure 5 showed the effect of absorbent dosage against percentage of dye removal of $C R$ on acid activated orange peel (AC OP) and acid activated rice husk (AC $\mathrm{RH})$. A series of absorption experiments was carried out with different absorbent dosages $(0.05,0.1,0.15,0.2,0.25,0.3 \mathrm{~g})$ at fixed concentration of $60 \mathrm{mg} / \mathrm{L}$ at constant volume of dye at $50 \mathrm{~mL}$ with constant speed of rotation $150 \mathrm{rpm}$ for 2 hours. The temperature was kept constant at $27^{\circ} \mathrm{C}$.

From Figure 5 it can be seen that the highest percentage of dye removal by AC OP was at absorbent dosage $0.25 \mathrm{~g}$ in CR dye, up to $100 \%$. The lowest percentage of dye removal by AC OP was at $0.05 \mathrm{~g}$ which was $19.27 \%$. It can be said that AC OP absorbs CR dye effectively compared to OP 150 and OP 425. However the best removal was obtained using $\mathrm{AC} \mathrm{RH}$ as the absorbent. The removal was $100 \%$ at $0.05 \mathrm{~g}$ of $\mathrm{AC} \mathrm{RH}$ itself. This showed that $A C R H$ removes dye efficiently even at lower dosage of absorbent.

Figure 6 showed the effect of absorbent dosage against percentage of dye removal of $A Y$ 36 dye on acid activated orange peel (AC OP) and acid activated rice husk ( $A C R H)$. A series of absorption experiments was carried out with different absorbent dosages $(0.05,0.1,0.15,0.2$, $0.25,0.3 \mathrm{~g}$ ) at fixed concentration of $60 \mathrm{mg} / \mathrm{L}$ at constant volume of dye at $50 \mathrm{~mL}$ with constant speed rotation $150 \mathrm{rpm}$ for 2 hours. The temperature was kept constant at $27^{\circ} \mathrm{C}$.

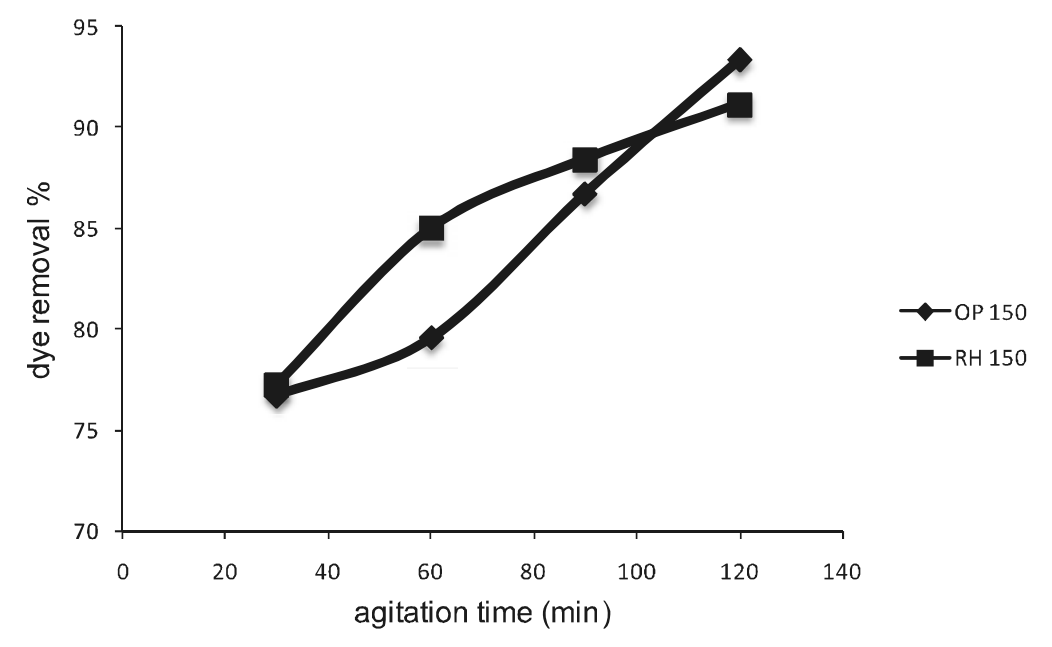

Fig. 9: Effect of agitation time on the percentage of dye removal for OP 150 and RH 150 in CR

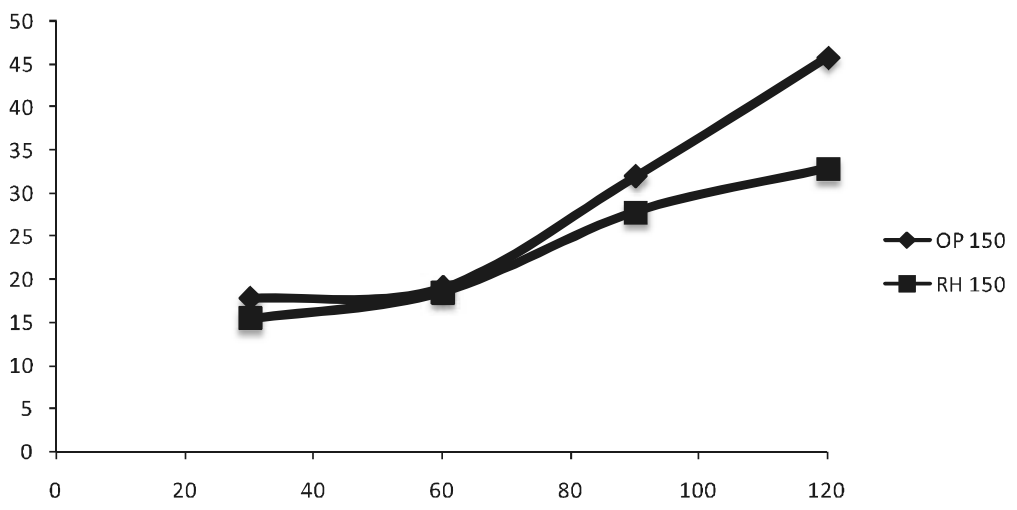

Fig. 10: Effect of agitation time on the percentage of dye removal for OP 150and RH 150 in AY 36 
Figure 6 showed the highest percentage of AY 36 dye removalby AC OP was at dosage 0.2 g. The removal was $100 \%$. The lowest removal percentage was at absorbent dosage of 0.05 , which only removed $17.5 \%$ of the dye. The usage of $A C$ OP as absorbent had to be terminated as the AC OP released a dark color when agitated with the dye. This went against the objective of this study, which was to ensure the environmental safety due to the usage of textile dye.

The reasons behind the great absorption capacity of $\mathrm{AC}$ OP and $\mathrm{RH}$ were due to the microporous and high surface area of the activated product. The absorption of bigger size compounds such as dyes, dextrines or natural organic materials requires a material with high mesopore contribution to the total pore volume of absorbent (LorencGrabowska \& Gryglewicz, 2006).

Pretreatment of $\mathrm{RH}$ can remove lignin, hemicellulose, reduce cellulose crystallinity and increase the porosity or surface area. In general, chemically modified or treated $\mathrm{RH}$ exhibits higher absorption capacities compared to unmodified $\mathrm{RH}$. Effect of initial concentration on the percentage of Congo Red and Acid Yellow 36 dye removal for orange peel and rice husk $<425 \mu \mathrm{m}$ and $>425 \mu \mathrm{m}$ Figure 7 showed the effect of initial concentration against percentage of dye removal of $\mathrm{CR}$ on $\mathrm{OP}$ 150, OP 425, $\mathrm{RH} 150$ and $\mathrm{RH}$ 425. A series of absorption experiments was carried out with different initial concentration of CR $(20,40,60,80$ and $100 \mathrm{mg} / \mathrm{L}$ ) at fixed volume of dye solution (50 $\mathrm{mL}$ ) with constant rotation speed 150rpm for 2 hours using absorbent dosage of $1.0 \mathrm{~g}$. The temperature was kept constant at $27^{\circ} \mathrm{C}$.

Figure 8 showed the effect of initial concentration against percentage of dye removal of AY 36 on OP 150, OP 425, RH 150 and RH 425. A series of absorption experiments was carried out with different initial concentration of CR $(20,40,60$, 80 and $100 \mathrm{mg} / \mathrm{L}$ ) at fixed volume of dye solution (50 $\mathrm{mL}$ ) with constant rotation speed 150rpm for 2 hours using absorbent dosage of $0.8 \mathrm{~g}$ for $\mathrm{RH}$ and 1.0 for OP. The temperature was kept constant at $27^{\circ} \mathrm{C}$.

Figure 7 and Figure 8 showed that the initial concentration of the dye did influence the dye removal rate. In most cases for $\mathrm{CR}$, the lower the concentration of the dye, the higher the dye removal percentage. This might be because of the low initial concentration of the dye which also meant that the particles of dye were also lower and the absorbent surface area was completely available for dye bindings without much competition.

The dye removal percentage was 96.11 $\%$ for OP 425 on CR dye at initial concentration of $20 \mathrm{mg} / \mathrm{L}$ whereas the removal decreased to 87.13 $\%$ when the initial concentration was changed to $100 \mathrm{mg} / \mathrm{L}$. This might be because of the concentrated binding site did not allow complete removal of dye at higher initial dye concentration. Meanwhilefor AY 36 dye removal using OP and $\mathrm{RH}$ as absorbents, the initial concentration with highest percentage of dye removal was at $80 \mathrm{mg} / \mathrm{L}$ for both OP 150 and OP 425. While the highest dye removal percentage for $\mathrm{RH} 150$ was at dye initial concentration of $20 \mathrm{mg} / \mathrm{L}$ at $41.66 \%$.

The results showed that the amount of dye absorbed was different depending on the products and dyes. It showed different optimum removal of each product on the dye. For example, as per OP 150 on CR, the optimum removal was up to 100 $\mathrm{mg} / \mathrm{L}$ while the optimum removal by OP 425 on CR was at $40 \mathrm{mg} / \mathrm{L}$.

After the optimum stage for removal was achieved, the increase in initial concentration resulted in lower dye removal percentage. This was because the surface area of the product became saturated for the binding of the dye molecules (Khaled et al., 2009).

Effect of agitation time on the percentage of Congo Red and Acid Yellow $\mathbf{3 6}$ dye removal for orange peel and rice husk $<\mathbf{4 2 5} \mu \mathrm{m}$

Figure 9 showed the effect of agitation time on percentage of removal of $\mathrm{CR}$ on $\mathrm{OP}<425 \mu \mathrm{m}$ (OP 150) and $\mathrm{RH}<425 \mu \mathrm{m}(\mathrm{RH} 150)$. A series of absorption experiment was carried out with different agitation times $(30,60,90,120 \mathrm{~min})$ at absorbent dosage of $1.0 \mathrm{~g}$, initial concentration of $60 \mathrm{mg} / \mathrm{L}$ without changing the volume of dye solution (50 $\mathrm{mL}$ ) with constant speed of $150 \mathrm{rpm}$. Temperature was kept constant at $27^{\circ} \mathrm{C}$. 
The results showed that the longer the agitation time, the higher the rate of dye removal. At minute 30 , the removal of CR bye OP 150 was 76.73 $\%$ while the removal of CR by $\mathrm{RH} 150$ was $77.27 \%$. The removal percentage increased to $93.37 \%$ using OP 150 and $91.18 \%$ using 150 when the agitation time was increased to 120 minutes (2 hours).

Same goes to the removal rate for AY36. The longer the agitation time, the higher the percentage of dye removal.Based from Figure 10, the percentage of removal by OP 150 at 30 minute was $17.81 \%$. It increased to $46.76 \%$ after agitated for 120 minutes. Meanwhile the percentage of removal by $\mathrm{RH} 150$ on AY 36 was $15.67 \%$ at 30 minutes, and increased up to $32.89 \%$ after agitated for 120 minutes.

This was due to the exposure of dye particles to the binding site of $\mathrm{OP}$ and $\mathrm{RH}$. The longer the particles were exposed to the binding site of the absorbents, the higher the percentage of dye removal. In the process of dye color absorption, the dye molecules have to first encounter the binding site and then diffuse to it. This phenomenon will take relatively long contact time (Malik, 2003).

\section{Statistical analysis}

T-test was performed under the confidence level of $99 \%$. The result is significant if the significance level is less than 0.01. Based from Table 1 , most of the results obtained achieved significance level less than 0.01 which indicated that the OP and $\mathrm{RH}$ were significant products for the removal of dye. The significance level was not up to the standard in the case of initial concentration manipulation of OP 150 and OP 425 on AY 36. Other than that, the agitation time of OP 150 on AY 36 also resulted in insignificant value of the t-test.

\section{CONCLUSION}

$\mathrm{OP}$ and $\mathrm{RH}$ are cheap and easily available agricultural by-products which can be used effectively in removing dye. The present investigation has shown that the granular form and acid pre-treated $\mathrm{OP}$ and $\mathrm{RH}$ can be effectively used as raw materials for the removal of Congo Red and Acid Yellow 36 dyes from aqueous solution. The results showed that acid-pretreated $\mathrm{OP}$ and $\mathrm{RH}$ have the highest dye removal percentage which was up to $100 \%$.

The study also showed that both $\mathrm{CR}$ and AY 36 were removed by absorbent with lower $\mathrm{pH}$ levels. This was because $C R$ and AY 36 were both anionic dyes, they reacted accordingly with their positively charged surface of the absorbent. Higher percentage of dye removal was also observed in smaller size absorbents compared to larger size absorbents. This was due to the larger surface area for the binding of dye molecules on the absorbents. During the study, problem aroused when the pretreated OP gave out a very dark color due to the acid treatment. This can be overcome with the usage of bleach before OP treatment and continuous washing with distilled water until the color fades off.

\section{ACKNOWLEDGEMENTS}

The authors are grateful to the Faculty of Agro Based Industry, Universiti Malaysia Kelantan, Jeli Campus for providing the financial support for the present study.

\section{Conflict of Interests}

The Authors declare that there is no conflict of interests regarding the publication of this article.

\section{REFERENCES}

1. Alpert, A.; Barnes, L.; Altenburg, M.;Delmar Thomson Learning, 2004.

2. Arami, M.; Limaee, N. Y.;Mahmoodi, N. M.; Tabrizi, N. S.; Journal of Colloid and Interface Science,2005,288(2), 371-376.

3. Asgher, M.;Bhatti,N. H.;Ecological Engineering,2012,38(1), 79-85.
4. Christie, R.M.;Woodhead Publishing, 2007.

5. Department of the Environment (DOE), 1996.

6. Ghosh, G. K.;APH Publishing Corporation, 2008.

7. Hardin, I. R.;Woodhead Publishing, 2007.

8. Hornung, D.;UK: LaurenceKing Publishing, 2004. 
9. Khaled, A.; Nemr, A. E.; El-Sikaily, A.; Abdelwahab, Ola;Desalination,2009,238, 210-232.

10. Lee, C. C.;Environmental Engineering Dictionary (4 ${ }^{\text {th }}$ Ed.); USA: Government Institutes, 2004.

11. Liang, S.;Guo, X.;Feng, N.; Tian, Q.;Journal of Hazardous Materials,2010,174, 756-762.

12. Lorenc-Grabowska, E.; Gryglewicz, G.;Dyes and Pigments, 2007,74(1), 34-40.

13. Malik, P. K.;Dyes and Pigment,2003,56(3), 239-249.

14. Pereira, L.; Madalena, A.;Environmental Protection Strategies for Sustainable
Development: Dyes-environmental Impact and Remediation. Netherlands: Springer Netherlands, 2012.

15. Ravindra, K. D.; Moray, D. N.; Thomas, D.D.; Sustainable Waste Management: Ecological Balance of Silicon Using Rice Hull Ash in Agriculture. The University of Michigan: Thomas Telford, 2003.

16. Rodriguez-Couto, S;Current Drug Metabolism,2009,10(9), 1048-1054.

17. Zulkifli, A. R.; Choong, M. C.; Noor, S. A.; Malaysia Environmental Quality Report, Department of Environment Malaysia, 2011. 